\title{
Feasibility Study And Establishing the Machining Process Parameter for Bio Medical Hip Implant of Titanium Material Using CNC Machine Through Conventional Route
}

\author{
Ashok Kumar Prasad, Palash Kumar Maji, S.Y.Pujar, Praveen Kumar \\ Central Mechanical Engineering Research Institute, Durgapur
}

\begin{abstract}
Hip replacement refers to the process in which a damaged hip joint is surgically replaced with an artificial implant. It has been observed that all implants are not safe for use and some can cause serious complications to patient after surgery. A total hip replacement comprised of replacement of entire hip structure using an artificial prosthesis, during this surgical procedure, a stem is inserted into the patient's femur for stability, and a ball replaces the head of the femur \& the socket is also replaced with an artificial cup. The hip implantation was usually cemented in place, but it is also find that some surgeons use a cementless approach instead. The hybrid total hip replacement uses a combination of both, implanting the cup without cement and setting the stem in place with cement. So far as the availability of specific prosthesis for specific patients it is very difficult more over the prosthesis which will be available are not properly matching with the patients requirements due to change in morphology of human structure. Hence it is understand that there is a requirement of feasibility study for machining of the prosthesis based on the specific patient's requirements. Considering the above need a network project has been undertaken by CSIR for the development of prosthesis through conventional route. The machining is being carried out by first taking the CT scan data of the patient using MIMICS software, and then this data is being analyzed with suitable load in ANSYS to find out the Stress and strain of this intact femur bone after that the CAD model of femoral stem had been prepared Solid with \& without collar, then FEA of femur bone carried out by placement of prosthesis in actual bone by meshing in ANSYS. The result shows that the hollow prosthesis has a better effect than the solid prosthesis as the weight is further reduced and the effect can be further improved by using Ti Alloy as prosthesis material. The machining is being carried out using CNC Machining centre Mikron $\mathrm{m} / \mathrm{c}$ by preparing the required programme as per the profile of the prosthesis and then the parting operation of the prosthesis is performed using CNC wire cut EDM machine, to get the final prosthesis.
\end{abstract}

Keywords: artificial hip implants, CNC machining, CT scan, femoral stem, Hip replacement.

\section{Introduction}

Hip replacements are the orthopedic surgical operation of an aged or injured natural hip joint by adding an artificial joint, or implant — date back three centuries [1]. Reasons for these implants are the same now as then: a fracture or similar injury to the hip, arthritis or a wearing down of the joint over time. The goal is to reduce pain and increase mobility. Although there are varied designs and models of hips built by several manufacturers, there are three basic components of an artificial hip and a stem that is inserted into the femur (thighbone), a ball that attaches to the top of the femur; and a cup that attaches to the pelvis. Modern implants, increasingly popular since the $1970 \mathrm{~s}$, are made from a combination of materials, including plastics, ceramics and metals [2]. Many of the most recent devices were metal-on-metal designs, created with the hope that hip replacements would last longer to give younger, active patients more pain-free mobility for more years.

If conservative treatments like physical therapy and pain medication fail to fix a hip problem, there are several surgical procedures that can provide a solution. Surgeons and patients will discuss the options before scheduling surgery. The decision is based on the age of the patient, as well as the unique problems with the hip joint. Technological developments and medical studies can also influence the decision. Every surgery comes with risks, but the risk can be minimized by choosing the safest, most appropriate procedure for each patient. 


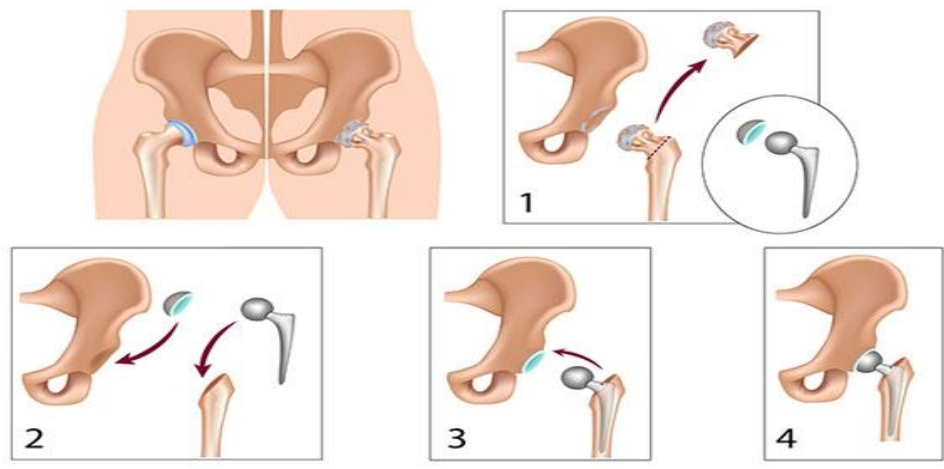

Fig.1. Schematic of total hip replacement (THR) surgery [8]; 1) Remove femoral head, 2) Insert Acetabulum and stem in femoral canal, 3) put prosthesis with femoral canal in ball and socket, 4) artificial hip prosthesis placement.

\subsection{Types of Hip Implant Devices:-}

These are the most common type of hip implants and have been around since the 1960s. Plastic has a smoother surface finish that allows for less friction while the ball moves within the socket. However, MoP implants produce a lot of plastic debris, which will eventually cause the implant to fail and could lead to a condition called osteolysis [6].

\subsubsection{Metal ball and metal cup:-}

MoM implants are very durable and can withstand the active lifestyle of younger patients. They can accept larger bearings and have wear process is nearly $70 \%$ less than implants made of other materials like plastic on metal [2]. However, their durability comes at a price. MoM hip implants shed metal particles that have been linked to a number of serious health issues like metallosis. Metal-on-metal implants have recently come under fire due to design flaws and early failure rates [3]. Several manufacturers - including DePuy and Stryker - have recalled one or more all-metal hip implant products.

\subsubsection{Ceramic ball and plastic cup: -}

Unlike the plastic used in the MoP device, the plastic used in these devices is very dense. Although these materials are reliable and provide for a very smooth surface, there is still the issue of wear debris and the potential for osteolysis.

\subsubsection{Ceramic ball and ceramic cup:-}

All-ceramic hips are known for their durability and reliability. They have been around since the early 1980s, but they were only recently approved for use in the United States [4]. Although the femoral ball is made from very hard clay that is wear-resistant, these devices have a history of producing a squeaking noise, and shattering. The first ceramic-on-metal hip received FDA approval in 2011. The goal is to avoid the problems of metal-on-metal implants.

\subsubsection{Metal-on-Metal Hip Implants:-}

Metal-on-metal hip implants produced one significant complication: metal ions can rub off of the devices and enter a recipient's bloodstream, creating a metal poisoning knows as metallosis [5]. Other complications with these implants include a loosening of the acetabular components, joint dislocation and, in one case a squeaky hip represents osteolysis problems [6]. These complications may lead recipients to pursue corrective actions that are both physical and financial. Many people with problematic artificial hips opt for revision surgery, a corrective procedure that gives them a new hip implant. Many of those same patients and others opt for legal action by suing device manufacturers, claiming the companies knew their hip systems were defective.

\subsection{Types of hip replacement procedures}

Total Hip Replacement A total hip replacement uses an artificial joint to replace the entire hip structure. During the procedure, a stem is inserted into the patient's femur for stability, and a ball replaces the head of the femur [2]. The socket is also replaced with an artificial cup. Hip implants are usually cemented in place, but some surgeons use a cementless approach instead. A hybrid total hip replacement uses a combination of both, implanting the cup without cement and setting the stem in place with cement. 
Feasibility study and establishing the machining process parameter for Bio Medical hip implant of..

\subsubsection{Partial Hip Replacement}

Partial hip replacements (hemi arthroplasty) are recommended when only one part of a hip needs treatment. In most cases, the acetabulum (also known as the socket or cup) is left intact and the head of the femur is replaced with a ball. Some partial hip replacements only address the acetabulum. A partial hip replacement is commonly used to correct a hip fracture occurring at the neck of the femur.

\subsubsection{Hip Resurfacing}

The primary goal of hip resurfacing is to avoid bone loss. The procedure can delay a total hip replacement in younger recipients, who are likely to outlive the original implant and require a second surgery later. It replaces the socket with an artificial cup and resurfaces the head of the femur instead of removing it. This is accomplished by cementing a covering on top of the femur. This component has a short stem that is inserted into the neck of the femur. Hip resurfacing is often used to help with arthritis.

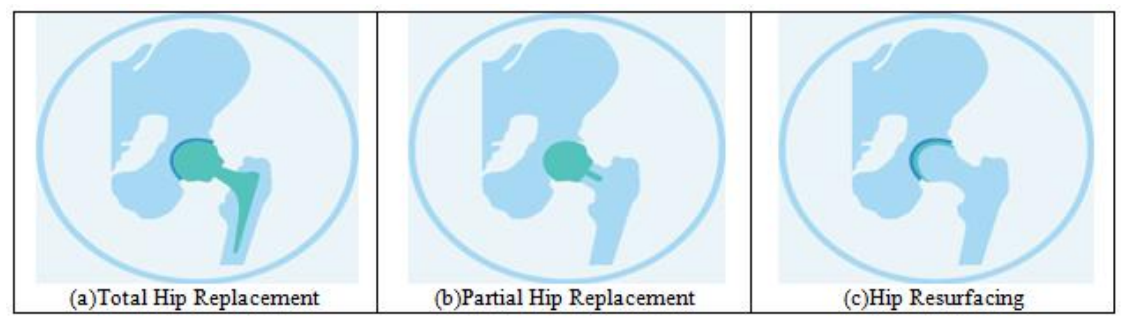

Fig.2 Types of Hip Replacement

\section{Main Objective Of The Study}

- To machine complex geometry.

- To reduce rejection rate.

- To produce component with dimensional accuracy.

- To improve surface finish.

- To reduce the manufacturing lead time as well as manufacturing cost.

- Technology transfer to the suitable industry to produce implants in large quantity to help the needed person's from the society.

III. Statement of The Problem

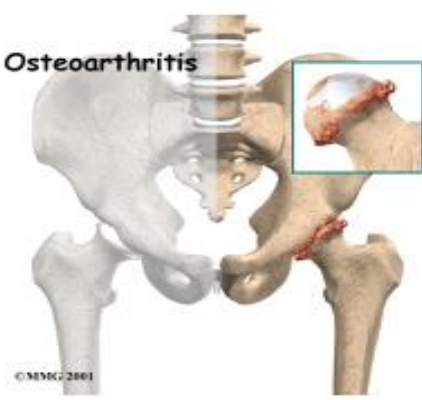

Fig.3 [Hip replacement surgery is performed for severe hip arthritis]

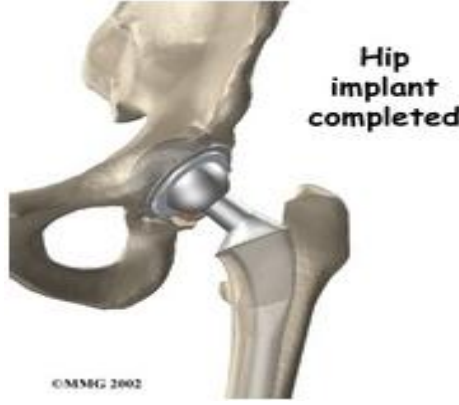

Fig.4 A hip replacement prosthesis replaces the ball and socket hip joint

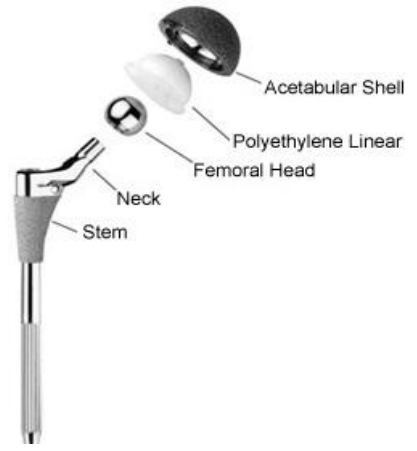

Fig.5 Various parts of a total hip joint 
Some researchers have developed the different shapes of stem less \& nonstemless hip prosthesis with new fabrication technology [7]. In this feasibility study we basically try to establish the machining route for the development of the tailored patient specific critical prosthesis through conventional method by using CNC machining facility. The main challenge was to make the femoral (stem) with dimensional accuracy removing the entire sharp corner providing acceptable surface finish. The problems faced before developing proper fixture and filling the cavity after first set up machining are:-

- Loading and un-loading was difficult \& not accurate.

- Face shift was observed between top \& bottom halves of the stem.

- Job clamping was not perfect as vice jaw was tilting the job.

- Frequent tool wear out \& tool breakage.

- Surface finish was not up to the mark due to chatter.

- Top face of the job was not coming parallel with respect to bottom face.

\subsection{Types of Hips:-}

Hip replacement (hip arthroplasty) is the rebuilding or replacement of the hip joint. The hip joint is made up of the followings,

$>$ Femoral head,

$>$ Top ball at the of the femur,

$>$ Acetabulum, the cup-shaped socket of the pelvis.

When a person walks or moves their legs, the femoral head moves within the Acetabulum in a similar fashion as a ball-and-socket joint. Hip implants are designed to mimic this natural movement as closely as possible. The primary differences among implants are with their size and the material. The Hip implant components were made of polyethylene (plastic), metal, ceramic or a combination of materials.

\section{Methodology}

In the first stage the CT scan data of Hip joint of a patient was taken then this data was being processed in MIMICS software to get the CAD model. After that suitable loading was imparted in ANSYS by inserted developed hip stem into the actual bone to obtained the stress and strain of this intact femur bone. Then the CAD model of femoral stem which is obtained through MIMICS software is being transferred to CNC machine either in STEP or IGES files and accordingly the programme has been prepared for the prosthesis to feed into the $\mathrm{CNC}$ machine. The blank has been prepared based on the model size keeping some machining allowance. The machining of hip prosthesis was being carried out using CNC micron milling machine in two steps; first rough machining then finishing operation was being carried out after the completion of CNC milling operation the parting operation of the implants were being performed using CNC wire EDM machine. After parting operation the two half's of the prosthesis were assembled using dwell pins \& screws.

\section{Challengability for the Machining of Titanium Alloy}

The milling operation of titanium is rather more difficult than turning operation. The milling operation the cutter mills the jobs during each revolution and due to property of the material the chips tend to adhere to the cutting edge of cutter and ultimately this will tends to damage the cutter. This problem to a some extent could be alleviated to a great extent by employing climb milling, instead of conventional milling. In this type of milling, the cutter is in contact with the thinnest portion of the chip as it leaves the cut, minimizing chip "welding". For slab milling, the work should move in the same direction as the cutting teeth, and for face milling, the teeth should emerge from the cut in the same direction as the work is fed.

In milling titanium, when the cutting edge fails, it is usually because of chipping. Thus, the results with carbide tools are often less satisfactory than with high speed steel. The increase in cutting speeds of 20-30\% which is possible with carbide tools compared with high speed steel tools does not always compensate for the additional tool grinding costs. Consequently, it is advisable to try both high speed steel and carbide tools to determine the better of the two for each milling job. The use of a water-base coolant is recommended for better result. Thus like stainless steel, due to low thermal conductivity of titanium material it is always advisable to use sufficient coolant during machining for the best dissipation of heat within the work piece.

Guide lines for good tool life and successful machining of titanium alloys can be assured if the following guidelines were observed:

- Maintain sharp tools to minimize heat buildup and galling.

- Use rigid setups between tool and work piece to counter work piece flexure.

- Use a generous quantity of cutting fluids to maximize heat removal.

- Utilize lower cutting speeds.

- Maintain high feed rates.

- Avoid interruptions in feed (positive feed).

- Regularly remove chips from machines. 


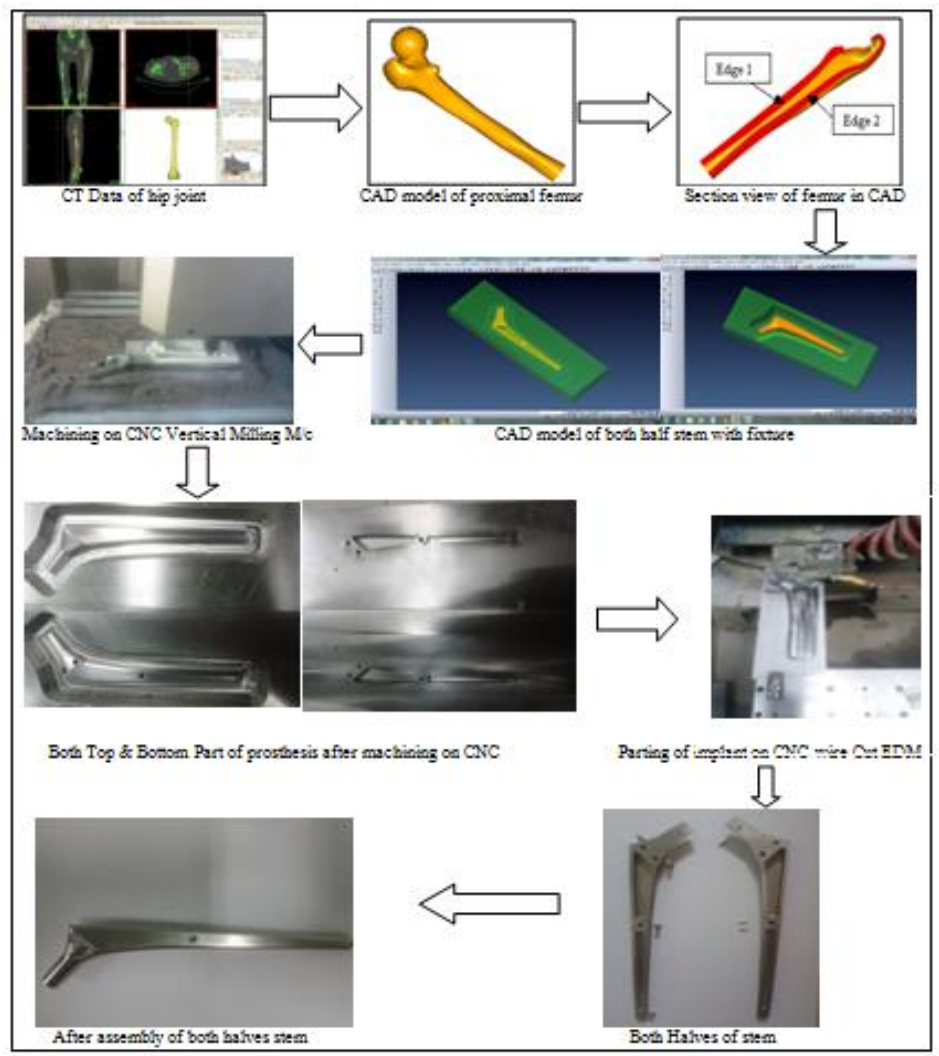

Fig.6 Shows the Flow Diagram for the Machining route of the Hip prosthesis from CAD model to actual prototype fabrication through conventional route.

Table 1: optimized cutting parameters used for machining of femoral stem using Titanium as material.

\begin{tabular}{|l|l|l|l|l|l|l|l|}
\hline S1 no. & Cutting tool details & $\begin{array}{l}\text { Cutting speed } \\
\text { in }(\mathrm{mt} / \mathrm{min})\end{array}$ & $\begin{array}{l}\text { Speed } \\
\text { in(RPM) }\end{array}$ & $\begin{array}{l}\text { Feed in } \\
(\mathrm{mm} / \mathrm{min})\end{array}$ & $\begin{array}{l}\text { Depth of } \\
\text { cut in mm. }\end{array}$ & $\begin{array}{l}\text { Step over in } \\
\mathrm{mm} .\end{array}$ & Remarks \\
\hline 01 & $\begin{array}{l}\text { Dia. 8.0 Solid Carbide } \\
\text { End Mill }\end{array}$ & 135 & 5372 & 760 & 0.30 & ----- & $\begin{array}{l}\text { Flood } \\
\text { supply was used for } \\
\text { machining } \\
\text { operation }\end{array}$ \\
\hline 02 & $\begin{array}{l}\text { Dia. 3.0 Cr ball nose } \\
\text { End Mill }\end{array}$ & 55 & 6000 & 750 & 0.05 & 0.03 & \\
\hline
\end{tabular}

Table 2.CNC Part Programme (Milling) for hip implant machining:

\begin{tabular}{|c|c|}
\hline CNC programming for roughing operation & CNC programming for finishing operation \\
\hline 0 BEGIN PGM HOLLOWIMPLANTROUGH MM & 0 BEGIN PGM HOLLOWIMPLNT MM \\
\hline 1; ISO FILE HOLLOWIMPLANTROUGH.HNC & 1; ISO FILE HOLLOWIMPLNT.HNC \\
\hline 2; WKF FILE HOLLOWIMPLANT2 IN1.WKF & 2; WKF FILE HOLLOWIMPLANT2 IN1.WKF \\
\hline 3 BLK FORM $0.1 \mathrm{Z}$ X+60.010 Y+89.784 Z-14.225 & 3 BLK FORM $0.1 \mathrm{Z}$ X+61.546 Y+91.241 Z-14.500 \\
\hline 4 BLK FORM $0.2 \quad X+281.081 Y+164.000 \mathrm{Z}+11.255$ & 4 BLK FORM $0.2 \quad X+279.556 \mathrm{Y}+162.521 \mathrm{Z}+9.996$ \\
\hline 5 ;END MILL DIAM 8 LENGH 80 & 5 ;BALL NOSE DIAM 3 LENGH 30 \\
\hline 6 TOOL CALL 1 Z S5372 & 6; GUIDE POINT AT TIP \\
\hline 7 CYCL DEF 32.0 TOLERANCE & 7 TOOL CALL 2 Z S6000 \\
\hline 8 CYCL DEF 32.1 T0.01 & 8 L Z+100.000 R0 FMAX M3 \\
\hline $9 \mathrm{~L} Z+100.000$ R0 FMAX M3 & \\
\hline 10 ;- & 12; PARALLEL PLANE \\
\hline 11; ROUGHING SPIRAL & $13 \mathrm{~L} X+279.556 \mathrm{Y}+112.992 \mathrm{R} 0 \mathrm{FMAX}$ \\
\hline $12 \mathrm{~L} X+225.125 \mathrm{Y}+141.923 \mathrm{R} 0 \mathrm{FMAX}$ & 14 L Z+9.996 FMAX \\
\hline $13 \mathrm{~L} Z+11.255$ FMAX & 15 L Z-11.500 FMAX \\
\hline $14 \mathrm{~L} Z+7.255 \mathrm{~F} 355$ & 16 L Z-13.000 F500 \\
\hline $15 \mathrm{~L} \mathrm{X}+225.409 \mathrm{Y}+141.811 \mathrm{Z}+5.724$ & $17 \mathrm{~L} \mathrm{Y}+112.955 \mathrm{Z}-13.334$ \\
\hline 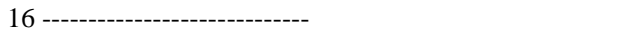 & 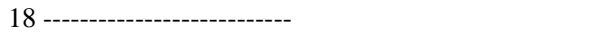 \\
\hline 30446 L X+67.261 Y+139.467 Z-10.225 & $405860 \mathrm{~L}$ Y+150.899 Z-13.000 \\
\hline 30447 L Z-6.225 & $405861 \mathrm{~L}$ Z-11.500 \\
\hline 30448 L Z+9.996 FMAX & 405862 L Z+9.996 FMAX \\
\hline 30449 M9 & 405863 M9 \\
\hline 30450 L Z+100.000 R0 FMAX & 405864 L Z+100.000 R0 FMAX \\
\hline 30451 M5 & 405865 M5 \\
\hline 30452 M30 & $405866 \mathrm{M} 30$ \\
\hline 30453 END PGM HOLLOWIMPLANTROUGH MM & 405867 END PGM HOLLOWIMPLNT MM \\
\hline
\end{tabular}


Feasibility study and establishing the machining process parameter for Bio Medical hip implant of..

Table 3. Comparison of cost for Orthopedic Surgery in India with implants.

\begin{tabular}{|l|l|l|l|}
\hline Procedure / Package & No. of Days & $\begin{array}{l}\text { Price (INR) - } \\
\text { Single Room }\end{array}$ & $\begin{array}{l}\text { Price (USD) } \\
\mathbf{( \$ @ ~ R s . 4 2 )}\end{array}$ \\
\hline Total Knee Replacement (Unilateral - Including PFC Implant) & 7 & 345000 & 8200 \\
\hline Total Knee Replacement (Bilateral - Including PFC Implant) & 10 & 630000 & 15000 \\
\hline Total Knee Replacement (Bilateral - Including PFC Implant) & 10 & 630000 & 15000 \\
\hline Total Knee Replacement (Unilateral - Including Hi-Flex Implant) & 7 & 325000 & 7750 \\
\hline Total Knee Replacement (Bilateral - Including Hi-Flex Implant) & 10 & 595000 & 14200 \\
\hline Total Hip Replacement (Unilateral - Including Uncemented Implant) & 7 & 330000 & 7850 \\
\hline Total Hip Replacement (Bilateral - Including Uncemented Implant) & 10 & 595000 & 14150 \\
\hline $\begin{array}{l}\text { Hip Resurfacing - Articular Surface Replacement -(Unilateral - } \\
\text { Including Basic ASR Implant) }\end{array}$ & 7 & 405000 & 9650 \\
\hline Hip Resurfacing - Articular Surface Replacement & 7 & 345000 & 8200 \\
\hline
\end{tabular}

\section{Conclusion}

It is understood from the above study of costing data that the orthopedic surgery in India is costlier and also it takes more time. But from the process which we have developed it is very clear that if this process could be adopted for the development of the patient specific hip implants than it is sure that patients would get very suitable implants which may not create much problem after surgery as with other available implants, secondly the implants cost will be reasonable and the implants will be made available to the patients at least within a time frame of 4-5 days (approx) from the CT scan data obtained. The another advantage of this new machining technology is that we have tried to reduce the further weight of the implants by providing hollowness which will lead to obtain the better stress \& strain properties and the patient will feel more comfort due the further reduction in weight of the implants.

\section{References}

[1]. Yousef Abu-Amer ${ }^{1}$,Isra Darwech ${ }^{2}$, John C Clohisy ${ }^{3}$,Aseptic loosening of total joint replacements: mechanisms underlying osteolysis and potential therapies, Arthritis Research \& Therapy Volume 9 Supplement 1, 2007:

[2]. Stephen Richard Knight, ${ }^{1}$ Randeep Aujla, ${ }^{2}$ and Satya Prasad Biswas ${ }^{3}$, Total Hip Arthroplasty - over 100 years of operative history, Orthop Rev (Pavia). 2011 Sep 6; 3(2): e16.

[3]. Cuckler JM ${ }^{1}$.The rationale for metal-on-metal total hip arthroplasty. Clin Orthop Relat Res., 2005 Dec; volume 441:132-6.

[4]. Francesco Traina, ${ }^{1}$ Marcello De Fine, ${ }^{1}$ Alberto Di Martino, ${ }^{1,2}$ and Cesare Faldini ${ }^{1}$ Fracture of Ceramic Bearing Surfaces following Total Hip Replacement: A Systematic Review Bio-med Research International Volume 2013 (2013), Article ID 157247, 8 pages.

[5]. Hallab N, Merritt K, Jacobs JJ "Metal sensitivity in patients with orthopedic implants". (March 2001), volume 83-A (3): 428-36.

[6]. Harris $\mathrm{WH}^{1}$, The problem is osteolysis, Clin Orthop Relat Res. 1995 Feb;volume (311):46-53.

[7]. Chen,T.H.,Lung,C.Y., Cheng, C.K., Biomechanical Comparison of A New Stemless Hip Prosthesis with Different Shapes-A Finite Element Analysis,Journal of Medical and biological Engineering , 2009,29(3),108-113.

[8]. Sadegh Rahmati ${ }^{~}$, Farzam Farahmand ${ }^{2}$ Farid Abbaszadeh ${ }^{3}$, Application of Rapid Prototyping for Development of Custom-Made Orthopedics Prostheses: Majlesi Journal of Mechanical Engineering, Vol. 3/ No. 2/ Winter-2010. 